\title{
Dicarboxylic Acid
}

National Cancer Institute

\section{Source}

National Cancer Institute. Dicarboxylic Acid. NCI Thesaurus. Code C120005.

An organic acid that contains oxygen and two carboxyl groups. 